out, receive no training in this important part of their duties.

Postgraduate teaching receives consideration, and in the Appendix, which some readers may, perhaps, regard as the best chapter, there is a trenchant criticism of the present teaching and examinations in the pre-clinical subjects, with constructive proposals for improvement.

Much of this book consists of analysis and philosophy. It is, on the whole, unlikely to make a powerful appeal to the mind of the average medical student of today, whose cultural background is not always on the highest level. To the teacher, responsible for the training of the general practitioner, it should be a real stimulus. To him especially we commend this pleasant and carefully thought out work.

M.D.

\section{THE PHYSIOPATHOLOGY OF CANCER}

Edited by F. Homburger, M.D., and W. H. FishMaN, Ph.D. Pp. xviii + I,031, with 152 illustrations. London: Cassell \& Co., Ltd. 1954. I35s.

The complex and divers tendencies in the development of cancer research have led to an accumulation of as yet partly inco-ordinated facts which not only confuse the student but are also not always available to the research worker engaged on a different line of attack. The authors of this treatise, well aware of the need for a comprehensive summing up, present an objective and critical review of the up to date achievements of cancer research. This volume, edited by Homburger and Fishman with 26 additional contributors, 25 American and one English, is sub-divided into four sections.

Part I, under the heading of biology, deals with the laboratory induction of tumours in various organs by carcinogenetic substances, with genetic and hormonal factors in the causation of experimental carcinomatosis, describes virus induced tumours and the virus theory and finally discusses nutritional influences on tumour behaviour.

Part II deals with the chemical and physical aspects of cancer and includes chapters on the mechanism of carcinogenesis, the chemistry of cancer tissue, the role of nucleoproteins in malignant growth, alterations in enzymatic activities in cancer patients, cyto- and histo-chemistry, experimental cancer therapy and experimental studies in carcinogenesis by radiation.

Part III is devoted to clinical investigation in cancer patients. This is, as well as Part IV, a complex chapter far less logically constructed than the two preceding ones and comprises complex subjects in no relationship to each other, e.g. steroid metabolism, environmental cancer and statistical studies, and a chapter headed 'Clinical Investigation in Cancer Research' which is the only section in this volume not doing credit to its title.

Part IV is a hybrid collection of most interesting articles falling under the common denominator 'Practical Applications.' It comprises five papers dealing with diagnostic tests, chemotherapy, exfoliative cytology, applied radiation therapy and the diagnostic use of radioactive isotopes.

This is a most remarkable volume, containing a wealth of information in concentrated form, well written, beautifully illustrated and firmly corroborated by an extensive literature. The authors have avoided the temptations of phantasy and speculation and have strictly adhered to experimental facts. Therein lies the great value of the book. It is foremost a work of reference for the scientist engaged in any one field of cancer research, but it will also be of great importance to the student whose interests reach beyond the boundaries of the medical curriculum.

\section{REVIEW OF PHYSIOLOGICAL CHEMISTRY}

By Harold A. Harpher, Ph.D. Fourth edition. Pp. 333, with 17 illustrations. Los Altos: Lange Medical Publications. 1953. \$4.00.

It will be freely admitted that the last decade has seen an enormous increase in the knowledge of physiochemical processes in relation to biological problems. The application of this knowledge to clinical medicine has heralded great advances in diagnosis and treatment. The problem of those who wish to advance the practice of scientific medicine is to incorporate the relevant facts into the already overburdened medical curriculum. This review of physiological chemistry is an attempt at a succint exposition suitable for those people, and they should include all medical students, who, having gained considerable knowledge from the standard texts, wish to review the entire subject in synoptic form. The book is well written, profusely illustrated with clear diagrams; it is comprehensive and well balanced. It should be useful for teachers preparing lectures and for busy practitioners who would like to bring themselves up-to-date with this difficult but important aspect of medical knowledge.

V.W.

\section{NEW DIMENSIONS OF DEEP ANALYSIS}

By Jan Ehrenwald, M.D. Pp. 3i6. London: George, Allen \& Unwin Ltd. 1954. 25 s.

The 'new dimensions' are those of extrasensory perception, and this book is a speculative review of the inter-relation between analytic psychotherapy and the psi phenomena-telepathy, clairvoyance, pre-cognition and the like. The author lists eight of his patients during whose therapy one or more unequivocal telepathic incidents were observed, and the first part of the book contains clinical observations on some of these. In Part II he examines the three levels of mental function; the ego, the id and the psi, and in Part III the ways in 